\title{
A Study on Magnitude and Pattern of Blood Pressure and Prevalence of Obesity among Diabetes Patients
}

\author{
Naisymol Mathew ${ }^{1 *}$, Abubaker Siddiq ${ }^{2}$ \\ ${ }^{1}$ Department of Pharmacy Practice, SJM College of Pharmacy, Chitradurga- 577502, \\ Karnataka, India \\ ${ }^{2}$ Department of Pharmacology, SJM College of Pharmacy, Chitradurga-577502, \\ Karnataka, India
}

\begin{abstract}
Background: Hypertension and obesity among patients with Type 2 Diabetes Mellitus in developing countries are perhaps even more harmful than in high-income countries. This study focuses primarily on assessing the magnitude and pattern of blood pressure in diabetes patients, secondly to assess the prevalence of obesity in diabetic patient. Method: A prospective observational study was carried out on 102 diabetes patients for a period of six months at Basaveshwara Medical College Hospital \& Research Centre, Chitradurga. Results: The study result shows that out of 102 prescription 48 patients were male (47.1\%) and 54 patients were females $(52.9 \%)$. Prevalence of obesity was found as $2(1.9 \%)$ patients belongs to underweight group, $56(55.1 \%)$ patients belongs to normal group, $42(41.1 \%)$ belongs to overweight group and $2(1.9 \%)$ are under obese group. Magnitude and pattern of blood pressure showed $27(26.5 \%)$ patients in optimal category, followed by $20(19.60 \%)$ patients in stage 1 category. Out of 102 diabetes patients prescriptions 14 minor interactions, 55 moderate interactions and no severe interactions were observed. Conclusion: The current study concludes that the most predominant pattern of blood pressure among the diabetic patients is stage 1 type and the overweight patients were more prevalent. Drug-drug interactions with anti diabetics were found and moderate type was predominant.

Key words: Antidiabetics, Diabetes Mellitus, Hypertension, Obesity, Prescription.
\end{abstract}

\section{Introduction:}

Diabetes is a group of metabolic disorder characterized by hyperglycemia resulting from defects in insulin secretion, insulin action or both and affects around 382 million people in 2013 and this number is expected to rise to 592 million by $2035 .{ }^{1}$ India leads the world with the largest number of diabetes patients and is often referred to as the diabetes capital of the world. ${ }^{2}$ According to estimates, India has the highest number of adults with diabetes reported at 50.8 millions in 2010 which is expected to rise to 87 millions by $2030 .{ }^{3}$ The prevalence of diabetes among adults has reached approximately $20 \%$ in urban populations and approximately 
$10 \%$ in rural populations. ${ }^{4}$ Indians are also believed to have a greater degree of insulin resistance and a stronger genetic predisposition to diabetes. ${ }^{5}$

It is well established that those developing type 2 diabetes have a higher body weight than control populations, reflecting the strong epidemiological association between obesity and development of diabetes. ${ }^{6}$ The sex specific and age-specific mean BMI values obtained in a study shows that females within 45-54 years are more prevalent. The prevalence rate of obesity $\left(B M I \geq 30 \mathrm{~kg} / \mathrm{m}^{2}\right)$ in females was three times higher in males with type $2 \mathrm{DM}(32 \% \text { vs } 11 \%)^{7}$

Diabetes and hypertension are closely related diseases. The prevalence of hypertension is 1.5 to 2 times greater in patients with diabetes mellitus as compared to non-diabetic subjects. ${ }^{8}$ The Seventh Report of the Joint National Committee on prevention, detection, evaluation, and treatment of high blood pressure(JNC 7) has recommended a downward shift in target blood pressure to $<130 / 80 \mathrm{~mm} \mathrm{Hg}$ in diabetes patient. ${ }^{9}$ Uncontrolled blood pressure in diabetes patients can cause severe threat in their life. Among hypertensives, $32.1 \%$ were stage I, $20.8 \%$ were stage II and $10.4 \%$ were in stage III hypertension category globally. ${ }^{10}$ Coexistence of diabetes and hypertension leads to increased cardiovascular morbidity and mortality. ${ }^{8}$

Recent recommendations from the American Diabetes Association and the European Association for the Study of Diabetes note that aggressive management of cardiovascular risk factors, which include high blood pressure and obesity, may be even more beneficial in patients with type 2 DM because of their increased risk of cardiovascular morbidity and mortality. The relative risk of cardiovascular disease for persons with diabetes is double or more than that of persons without diabetes, although the absolute risk of cardiovascular disease varies around the world. Hypertension and obesity among patients with type 2 DM in developing countries are perhaps even more harmful than in high-income countries, where access to health care and adequate prevention programs help manage cardiovascular risk factors and can delay complications. ${ }^{11}$

As inadequately controlled hypertension remains a risk factor for coronary artery disease, an attempt is made to screen the diabetic patients for hypertension to assess the physician's conduct in identifying them and to create awareness among them about rational use of medicines.

\section{Methods:}

This was a hospital based prospective observational study conducted in the General Medicine Department of Basaveshwara Medical College \& Hospital, Chitradurga. The study was conducted over a period of six months from October 2017 to March 2018. The study was approved by the Institutional Ethical Committee of Sri Jagadguru Mallikarjuna Murugharajendra College of Pharmacy, Chitradurga. Vide number: SJMCP/IEC/PHARM D/25/17-18.

\section{Inclusion Criteria}

- Patients on anti-diabetic treatment for a minimum of 1 year.

- Patients of general medicine department.

- Subjects of both genders.

\section{Exclusion Criteria}

- Patients who refuse to give consent

- Patients who are severely ill.

- Psychiatric patients with diabetes.

\section{Study Procedure:}

A total of 102 diabetes patients who satisfied the study criteria and agreed to participate in this study were included in the study. Patient's demographic details, complaints, history, diagnosis, and prescribed drugs will be collected from the medical records of the patient and interview with patients or their care takers and 
will be documented in a suitably designed data collection form. BP will be recorded for all the study subjects using a sphygmomanometer by the auscultatory method. Weight and height of the subject is obtained to calculate their BMI. Indian Guidelines on Hypertension (I.G.H) III criteria was used to classify the study subjects into optimal, normal, high-normal and stages I, II, and III hypertension categories.

\section{Statistical Procedure:}

Collected data was entered in Microsoft Excel and assessed the data by using percentage or proportion either as pictorial representation in the form of bar diagram or pie chart or tabular form.

\section{$\underline{\text { Results }}$}

\section{Demographic Profile of the Patients}

A total of 102 Diabetes patients were enrolled in the study according to study criteria after obtaining informed consent, which showed that 48 were males and 54 were females. The results are shown in Figure.1.

\section{Distribution of Patients according to Age group}

In the current study, patients were divided into six groups based on age classification. Out of 102 patients the highest frequency was in 51-60 years group. There were no patients from Children and Adolescent age group. The results are graphically represented in Figure No. 2.

\section{Distribution of Blood pressure pattern:}

In the current study the patients were divided into eight groups based on pattern of blood pressure. The results are shown in Table. 1.

\section{Distribution of Prevalence of Obesity:}

In the present study patients were classified based on BMI into four groups. The results are shown in Table. 2.

The prevalence of $\mathrm{BMI} \geq 25 \mathrm{~kg} / \mathrm{m}^{2}$ is calculated as follows:

Total no. of Diabetes mellitus patients enrolled in the study $(\mathrm{N})=102$

Total no. of patients with BMI $\geq 25 \mathrm{~kg} / \mathrm{m}^{2}$ enrolled in the study $(\mathrm{n})=45$

Prevalence $=\frac{\mathrm{N} \times 100}{\mathrm{n}}=\frac{45 \times 100}{102}=44.1 \%$

\section{Distribution according to Gender in Obese and Overweight Patients:}

In the current study among 102 diabetes patients enrolled, 44 patients were having BMI value $\geq 25 \mathrm{~kg} / \mathrm{m}^{2}$ which includes both overweight and obese patients. The results are shown in Table. 3

\section{Distribution of Drug-Drug interactions with Antidiabetics :}

In present study, out of 102 diabetes patients prescriptions 14 minor interactions, 55 moderate interactions and no severe interactions were observed. The results are shown in the Table. 4. 


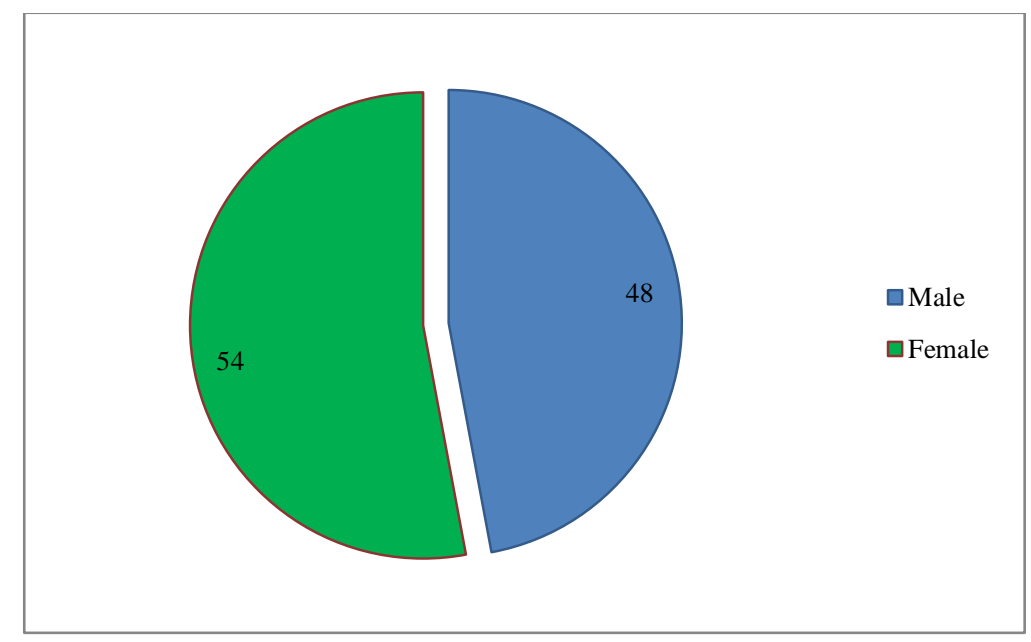

Fig 1: Distribution according to Gender $(n=102)$

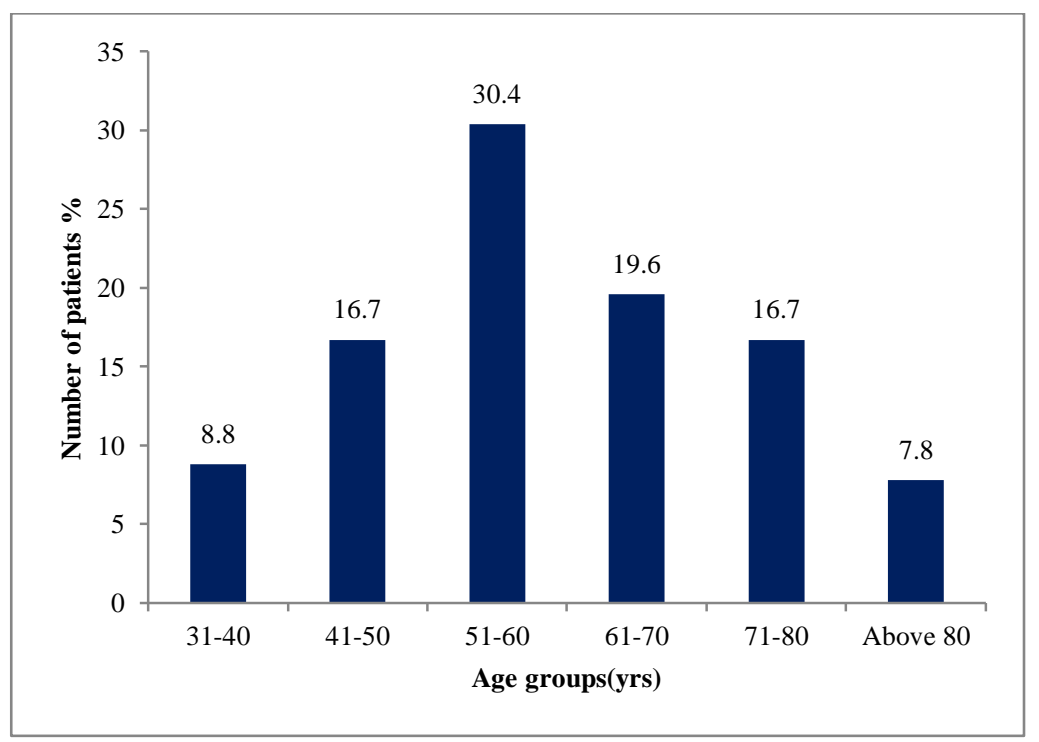

Fig.2. Distribution according to Age

Table. 1. Distribution of blood pressure pattern

\begin{tabular}{|l|l|l|l|}
\hline $\begin{array}{l}\text { Sl } \\
\text { no. }\end{array}$ & Pattern of BP & Frequency(n=102) & Percentage(\%) \\
\hline 1 & Optimal & 27 & 26.5 \\
\hline 2 & Normal & 17 & 16.7 \\
\hline 3 & High normal & 11 & 10.8 \\
\hline 4 & Stage 1 & 20 & 19.60 \\
\hline 5 & Stage 2 & 9 & 8.8 \\
\hline 6 & Stage3 & 10 & 9.8 \\
\hline 7 & Grade 1 & 3 & 2.9 \\
\hline 8 & Grade 2 & 5 & 4.9 \\
\hline & Total & 102 & 100 \\
\hline
\end{tabular}


Table. 2 Distribution of Prevalence of Obesity (n=102)

\begin{tabular}{|l|l|l|l|}
\hline $\begin{array}{l}\text { Sl } \\
\text { no. }\end{array}$ & BMI status & Frequency $(\mathbf{n}=\mathbf{1 0 2})$ & Percentage(\%) \\
\hline 1 & Underweight & 2 & 1.9 \\
\hline 2 & Normal & 55 & 55.1 \\
\hline 3 & Overweight & 42 & 41.1 \\
\hline 4 & Obese & 2 & 1.9 \\
\hline & Total & 102 & 100 \\
\hline
\end{tabular}

Table. 3. Distribution of gender in obese and overweight patients

\begin{tabular}{|l|l|l|l|}
\hline Sl. No & Gender & Frequency $(\mathbf{n}=\mathbf{4 5})$ & Percentage\% \\
\hline 1. & Male & 21 & 47.7 \\
\hline 2. & Female & 23 & 52.3 \\
\hline & TOTAL & 44 & 100 \\
\hline
\end{tabular}

Table. 4. Distribution of Drug-Drug Interactions with Antidiabetics ( $n=102)$

\begin{tabular}{|l|l|l|l|}
\hline Sl No. & Type & Frequency & Percentage \\
\hline 1 & Minor & 14 & 20.3 \\
\hline 2 & Moderate & 55 & 79.7 \\
\hline 3 & Severe & 0 & 0 \\
\hline & Total & 69 & 100 \\
\hline
\end{tabular}

\section{Discussion}

In the current study out of 102 diabetes patients, 48(47.1\%) were males and 54(52.9\%) were females. A similar study conducted by Patel B et al showed that out of 114 patients 66 (57. 9\%) were females and 48 $(42.41 \%)$ were males ${ }^{12}$. Thus a slight preponderance of females was noticed in both the studies.

In the current study out of 102 diabetes patients, maximum number of patients comes under age group 51-60 (30.4\%) and minimum number of patients were in age group above 80(7.8\%). A similar study was conducted by Alex SM et al showed a concordance result in which majority of patients were in age group 5160 years $(39.6 \%){ }^{1}$

In the current study the prevalence of obesity among diabetes patients were monitored. Out of 102 patients, prevalence of $\mathrm{BMI} \geq 25 \mathrm{~kg} / \mathrm{m}^{2}$ in patients is approximatelty $44.1 \%$ in which $42.1 \%$ of them were overweight and $1.9 \%$ of them were obese $\left(\mathrm{BMI} \geq 30 \mathrm{~kg} / \mathrm{m}^{2}\right)$. A similar study was carried out by Al-Sharafi BA et $\boldsymbol{a l}$ and concluded $43.5 \%$ were overweight and $11 \%$ were obese. Thus concordance results were obtained in both the studies. ${ }^{7}$

In the present study, 27(26.5\%) diabetic patients were found with optimal BP, 17(16.7\%) with normal BP, 11(10.8\%) with high normal BP, 20(19.6\%) with STAGE 1 HTN , 9(8.8\%) with STAGE 2 HTN, 10(9.8\%) with STAGE 3 HTN, 3(2.9\%) with Grade 1 HTN and 5(4.9\%) with Grade 2 HTN. A similar study was conducted by Basavegowda $\mathbf{M}$ et al among 104 diabetes patients but predominance was for stage 1 HTN followed by optimal HTN. ${ }^{8}$

In the current study, 69 interactions were noticed among which 14(20.3\%) were minor drug interactions, 55(79.7\%) were moderate interactions in which aspirin+ glimepride was predominant $(53.3 \%)$ and zero severe drug interaction was observed. A similar study was conducted by Kumar MA et al but showed less concordance with the present study. ${ }^{13}$

In the current study among 102 diabetes patients enrolled, 44 patients were having BMI value $\geq 25 \mathrm{~kg} / \mathrm{m}^{2}$ which includes both overweight and obese patients and among them age specific data shows that the BMI values were more in females(53.4\%) than in males(46.6\%). A similar study done by Al-Sharafi BA et al and 
the sex specific data in their result shows that females had a higher prevalence of the BMI $\geq 25(87.7 \%)$ in contrast to males $(83.1 \%)^{7}$

\section{Conflict of Interest}

Hereby declaring that there is no conflict of interest.

\section{References}

1. Alex SM et al. Drug Utilization Pattern of Anti-Diabetic Drugs Among Diabetic Outpatients in a Tertiary Care Hospital. Asian Journal of Pharmaceutical and Clinical Research. 2015; 8(2): 144-146.

2. Mithal A, Majhi D, Shunmugavelu M. Prevalence of dyslipidemia in adult Indian diabetic patients: A cross sectional study. Indian Journal of Endocrinology and Metabolism. 2014;18(5):642-47.

3. Deb T, Chakrabarty A, Ghosh A. Adverse drug reactions in Type 2 diabetes mellitus patients on oral antidiabetic drugs in a diabetic outpatient department of a tertiary care hospital in the Eastern India. International Journal of Medical Science and Public Health. 2017; 6(3): 554557doi:10.5455/ijmsph.2017.0423203102016.

4. Ramachandran A, Snehalatha C. Current scenario of diabetes in India. Journal of Diabetes. 2009; 1(1): 18-28doi:10.1111/j.1753-0407.2008.00004.x.

5. Tripathy JP, Thakur JS, Jeet G, Chawla S, Jain S, Pal A, Prasad R, Saran R. Prevalence and risk factors of diabetes in a large community-based study in North India: results from a STEPS survey in Punjab, India. Diabetology and Metabolic Syndrome. 2017; 9(8): 210-218.

6. Daousi C, Casson IF, Gill GV, MacFarlane IA, Wilding JPH, Pinkney JH. Prevalence of obesity in type 2 diabetes in secondary care: association with cardiovascular risk factors. Postgraduate Medical Journal. 2006; 82: 280-284doi:10.1136/pmj.2005.039032.

7. Al-Sharafi BA, Gunaid AA. Prevalence of Obesity in Patients With Type 2 Diabetes Mellitus in Yemen. International Journal of Endocrinology and Metabolism. 2014; 12: 1-5, doi:10.5812/ijem.13633.

8. Basavegowda M, Shankarappa KH, Channabasappa AN, Marulaiah SK, Hathur B. Magnitude and pattern of hypertension among diabetics; risk prediction for stroke and myocardial infarction. Journal of Mahatma Gandhi Institute of Medical Sciences. 2014; 19(1): 51-54.

9. Haydeh H, Dorari SS. Hypertension and Type 2 Diabetes: A Cross-sectional Study in Hospitalized Patients in Quchan, Iran. Iranian Journal of Diabetes and Obesity. 2013; 5(1): 21-26.

10. American Diabetes Association. Standards of medical care in Diabetes: Diabetes Care. 2008; 31(1): $112-54$.

11. Colosia AD, Palencia R, Khan S. Prevalence of hypertension and obesity in patients with type 2 diabetes mellitus in observational studies: a systematic literature review. Diabetes, Metabolic Syndrome and Obesity: Targets and Therapy. 2013; 6: 327-338doi:10.2147/DMSO.S51325.

12. Patel B, Oza B, Patel KP, Malhotra SP, Patel VJ. Pattern of anti-diabetic drugs use in type 2 diabetic patients in a medicine out-patient clinic of a tertiary care teaching hospital. International Journal of Basic \& Clinical Pharmacology. 2013;2(4):485-491doi:10.5455/2319-2003.ijbcp20130826.

13. Kumar MA, Nizar A, Shailaja K, Jayasutha J, Ramasamy C. A study on prescribing pattern and potential drug-drug interactions in type 2 diabetes mellitus(inpatients) in a tertiary care teaching hospital. Der Pharmacia Lettre 2011;3(4):13-19. 